\title{
Effect of surface preparations on contact resistivity of TiW to highly doped n-InGaAs
}

\author{
Vibhor Jain ${ }^{1}$, Ashish K. Baraskar ${ }^{1}$, Mark A. Wistey ${ }^{1,2}$, Uttam Singisetti ${ }^{1}$, Zach Griffith ${ }^{3}$, Evan Lobisser ${ }^{1}$, \\ Brian J. Thibeault ${ }^{1}$, Arthur. C. Gossard ${ }^{1,2}$, Mark. J. W. Rodwell ${ }^{1}$ \\ ${ }^{1}$ Electrical and Computer Engineering Department, University of California Santa Barbara, Santa Barbara, CA \\ 93106-9560 \\ ${ }^{2}$ Materials Department, University of California Santa Barbara, Santa Barbara, CA 93106-5050 \\ ${ }^{3}$ Teledyne Scientific \& Imaging, Thousand Oaks, CA 91360 \\ Phone: (805) 893-8044, Email: vibhor@ece.ucsb.edu
}

\begin{abstract}
We report the effects of UV-ozone oxidation, oxide removal etch chemistry (dilute $\mathrm{HCl}$ or concentrated $\mathrm{NH}_{4} \mathrm{OH}$ ), semiconductor doping, and annealing on the contact resistivity $\left(\rho_{c}\right)$ of $\mathrm{Ti}_{0.1} \mathrm{~W}_{0.9}$ refractory alloy to ntype InGaAs. The semiconductor surface was oxidized through exposure to UV-ozone, then subsequently etched by either dilute $\mathrm{HCl}$ or concentrated $\mathrm{NH}_{4} \mathrm{OH}$ before TiW contacts were deposited by blanket sputtering. InGaAs samples doped at $5 \times 10^{19} \mathrm{~cm}^{-3}$, treated with 10 minutes of UV-Ozone then one minute dilute $\mathrm{HCl}$ exhibited $\rho_{c}$ of $(1.90 \pm 0.35) \times 10^{-8} \Omega-\mathrm{cm}^{2}$. The contacts are thermally stable at least to $400{ }^{\circ} \mathrm{C}$ where after one minute anneal, $\rho_{c}$ reduced to $(1.29 \pm 0.28) \times 10^{-8} \Omega-\mathrm{cm}^{2}$. TiW contacts on samples having same active dopants, with no UV-ozone oxidation and only 10 seconds of concentrated $\mathrm{NH}_{4} \mathrm{OH}$ etch exhibit $\rho_{c}$ of $(2.49 \pm 0.40) \times 10^{-8}$ $\Omega-\mathrm{cm}^{2}$.
\end{abstract}

\section{INTRODUCTION}

High speed electronic devices require very low resistance metal semiconductor ohmic contacts which remain stable under high current bias and thermal stress as transistors are scaled towards $\mathrm{THz}$ bandwidths. Geometric scaling laws show that doubling transistor bandwidths requires a four-fold reduction in contact resistivity $\left(\rho_{c}\right)(1-2)$. For simultaneous $f_{t}$ and $f_{\max }$ of greater than 1-THz in InP HBTs, emitter and base contact resistivities less than $2 \times 10^{-8} \Omega-\mathrm{cm}^{2}$ are specified (3). InP FETs have similar requirements of low contact resistance for high speed operation (1).

Traditionally titanium (Ti) has been used to make lowresistance contacts to n-InGaAs. However, under thermal stress and cycling, Ti-based ohmic contacts deteriorate making $\mathrm{Ti}$ incompatible with high temperature processing and also raising concerns for high current density operations (4-5). Low resistance ohmic contacts to III-V semiconductors are attainable by alloying AuGe eutectic and semiconductor (6) but the semiconductor surfaces must be free of surface oxides and defects before metal deposition. Contact resistivity of 4.3 $\times 10^{-8} \Omega-\mathrm{cm}^{2}$ has been reported on $\mathrm{n}-\mathrm{InGaAs}$ by using an $\mathrm{Ar}^{+}$ sputter clean of the surface prior to depositing $\mathrm{Ti} / \mathrm{Pt} / \mathrm{Au}$ contacts (7). Very low resistivity contacts exhibiting $\rho_{c}$ of 0.5 $\times 10^{-8} \Omega-\mathrm{cm}^{2}$ between Ti and $\mathrm{n}^{+}$-InAs have been reported in (8) but the surface preparation procedures are not described.
We previously reported that the n-InGaAs surfaces treated with UV-ozone plus concentrated $\mathrm{NH}_{4} \mathrm{OH}$ could reduce contact resistivity without the use of $\mathrm{Ti}(5,9)$. Follow up studies by secondary ion mass spectroscopy (SIMS) revealed that the reported samples contained a thin, unintentional layer of $\mathrm{Ti}$ (less than $1 \mathrm{~nm}$ ) at the metal (TiW)-semiconductor interface. In addition, InGaAs regrowth studies from our laboratory onto samples prepared using an $\mathrm{NH}_{4} \mathrm{OH}$ rinse after UV-ozone treatment led to poor epitaxial regrowth, suggesting a substantial oxide layer was not removed. With this new data, we believe that $\mathrm{Ti}$, rather than $\mathrm{NH}_{4} \mathrm{OH}$, is responsible for the low contact resistivity reported in (5).

Ex-situ contacts have been observed to be very sensitive to surface preparation techniques because the semiconductor surface rapidly becomes oxidized and/or contaminated in the time between surface preparation and metal deposition. In this paper we report a systematic study of how the resistivity of exsitu refractory TiW contacts is affected by UV-ozone oxidation, oxide removal etch chemistry (dilute $\mathrm{HCl}$ or concentrated $\mathrm{NH}_{4} \mathrm{OH}$ ), n-type doping of semiconductor with $\mathrm{Si}$ and anneal temperature. Here, in the TiW metal contacts, thin interfacial metal layers are avoided in order to make the process more robust and reproducible. Additional studies were performed to ensure the absence of any unintentional interfacial metal layers for the results reported. 


\section{FABRICATION}

Structures shown in Fig. 1 were grown by solid source molecular beam epitaxy (MBE) on (100) semi-insulating InP substrates. The Si-doped InGaAs layer had an electron concentration varying from $5 \times 10^{19} \mathrm{~cm}^{-3}$ to $5 \times 10^{18} \mathrm{~cm}^{-3}$ for the wafers used as determined by Hall measurements. The samples were exposed to UV-ozone for varying times and then treated with either 60 seconds $1: 10 \mathrm{HCl}: \mathrm{H}_{2} \mathrm{O}$ and 60 seconds DI rinse (dilute $\mathrm{HCl}$ etch), or 10 seconds concentrated $\mathrm{NH}_{4} \mathrm{OH}$ $(14.8 \mathrm{~N})$ with no DI rinse (5). The samples were then immediately loaded for blanket Ar-sputtering deposition of TiW (90\% W alloy). Blanket metal deposition avoids the liftoff step which exposes the semiconductor surface to photoresist. Photoresists tend to react with etchants used during surface preparation. Sometimes photoresist residue is also left after lithography which is removed by oxygen plasma that may cause damage to the semiconductor surface. $\mathrm{Ti} / \mathrm{Au} / \mathrm{Ni}(20 / 150 / 50 \mathrm{~nm})$ was deposited by electron-beam evaporation and lifted off to define transmission line model (TLM) pads. With Ni as the etch mask, TiW was then etched in $\mathrm{SF}_{6} / \mathrm{Ar}$ using inductively coupled plasma. Next, a wet etch

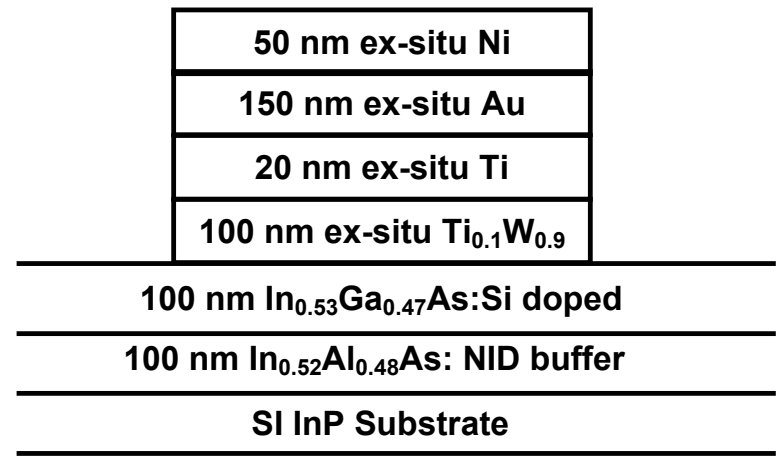

Fig 1: Cross-section schematic of the metal-semiconductor contact layer structure

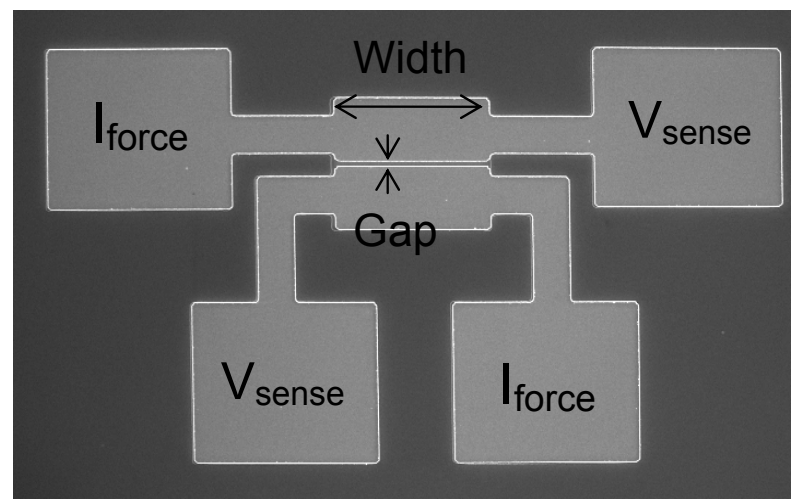

Fig 2: SEM image of the TLM pad with 600nm gap indicating the current source and voltage measurement pads was done to remove semiconductor down to semi-insulating InP and isolate the TLM patterns. A typical TLM pattern is shown in Fig 2. For annealing tests, samples were rapid thermal annealed for 60 seconds at $250-400{ }^{\circ} \mathrm{C}$ in $\mathrm{N}_{2}$ environment.

\section{RESULTS AND ANALYSIS}

Resistance was measured at room temperature on an Agilent $4155 \mathrm{C}$ semiconductor parameter analyzer using the four point probe technique to eliminate probe and interconnect parasitic resistances from the measurement. TLM pad spacing from 0.6-25 $\mu \mathrm{m}$ were verified using scanning electron microscopy (SEM). TLM contact pads are designed so that the resistance of the path common to current bias and voltage measurement is only measured. Thick metal pad $(320 \mathrm{~nm})$ on semiconductor reduces the effect of metal resistance on measurement. Interchanging the bottom pair of $\mathrm{I}_{\text {force }}-\mathrm{V}_{\text {sense }}$ probes (Fig 2) caused less than $15 \%$ shift in measured contact resistivity. A plot of TLM resistance as a function of gap spacing for different surface treatments is shown in Fig 3. Sheet resistance and contact resistivity were calculated from the plot as mentioned in (10). Sheet resistance of the samples with $\mathrm{NH}_{4} \mathrm{OH}$ and $\mathrm{HCl}$ treatment is different due to difference in carrier mobility data which resulted from different growth conditions (mobility $\sim 870 \mathrm{~cm}^{2} \mathrm{~V}^{-1} \mathrm{~s}^{-1}$ for samples to be treated with dilute $\mathrm{HCl}$ and $\sim 540 \mathrm{~cm}^{2} \mathrm{~V}^{-1} \mathrm{~s}^{-1}$ for those to be treated with concentrated $\mathrm{NH}_{4} \mathrm{OH}$ ). However, active dopant concentration is same for both the cases.

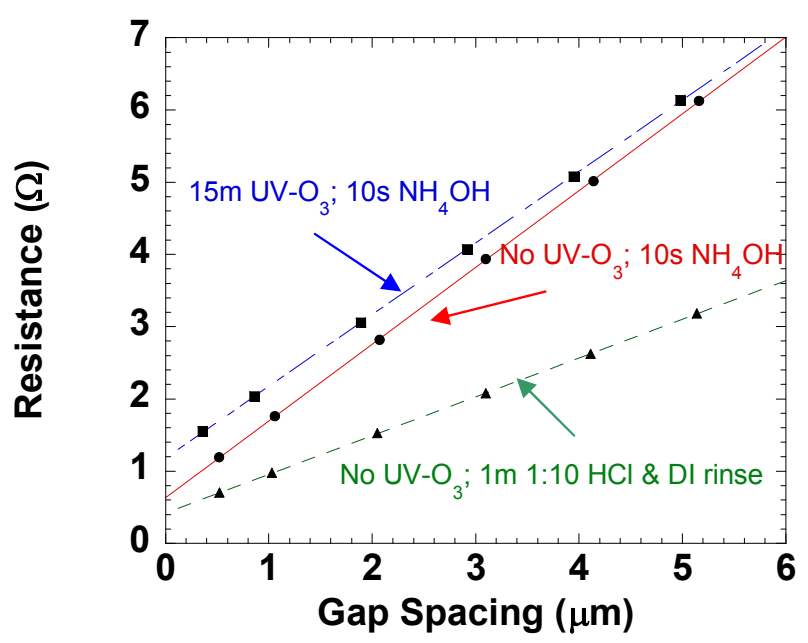

Fig 3: Measured resistance as a function of pad spacing for the contacts from $0.6 \mu \mathrm{m}$ to $6 \mu \mathrm{m}$ gap

\section{A. UV-Ozone Oxidation and Etch Chemistry}

The variation in contact resistivity with UV-ozone oxidation time for different etch chemistries is shown in Fig 4. Active dopant concentration for all these samples was kept same at 5 


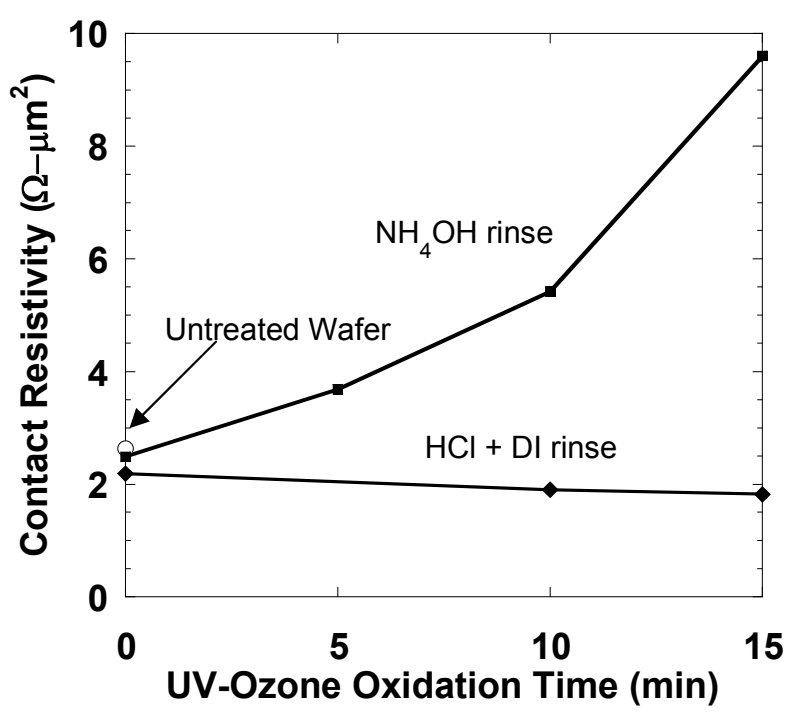

Fig 4: Contact resistivity variation with UV-ozone oxidation time for two different oxide-removal etch chemistries

$\times 10^{19} \mathrm{~cm}^{-3}$. The contact resistivity for $\mathrm{NH}_{4} \mathrm{OH}$ etched samples is observed to increase with oxidation time. It increases from $(2.49 \pm 0.40) \times 10^{-8} \Omega-\mathrm{cm}^{2}$ with no oxidation to $(9.61 \pm 0.93)$ $\times 10^{-8} \Omega-\mathrm{cm}^{2}$ after 15 minutes of oxidation. XPS data also shows an increase in surface oxygen content from $26 \%$ to $41 \%$. Therefore, $\mathrm{NH}_{4} \mathrm{OH}$ etch is not sufficient to remove surface oxides formed during UV-ozone oxidation. Samples with an increased etch time and same oxidation time also exhibit similar contact resistivity. $\rho_{c}$ of $(5.42 \pm 1.01) \times 10^{-8}$ $\Omega-\mathrm{cm}^{2}$ was measured for samples with 10 minutes UV-ozone and 10 seconds $\mathrm{NH}_{4} \mathrm{OH}$ etch while 30 seconds long etch samples exhibited $\rho_{c}$ of $(5.37 \pm 0.99) \times 10^{-8} \Omega-\mathrm{cm}^{2}$. Therefore, even an extended concentrated $\mathrm{NH}_{4} \mathrm{OH}$ etch is not effective in removing surface oxides in the case of long UV-Ozone oxidation (longer than 5 minutes based on the observed contact resistivities), causing an increase in the measured contact resistivity.

The contact resistivity for $\mathrm{HCl}$ samples was almost constant with oxidation time, indicating that the $\mathrm{HCl}$ etch removed oxides from the surface. This is also evident from XPS data where the surface oxygen content was found to be similar $(\sim 13-15 \%)$ for the same etch time but different oxidation times. Contact resistivity decreased slightly with increase in oxidation time, from $(2.19 \pm 0.38) \times 10^{-8}$ to $(1.82 \pm 0.34) \times 10^{-}$ ${ }^{8} \Omega-\mathrm{cm}^{2}$ ( 0 to 15 minute oxidation time). Although this slight decrease falls within the error margins, it could possibly be attributed to removal of hydrocarbon contamination by ozone followed by complete removal of the oxide by $\mathrm{HCl}$. XPS analysis shows $7 \%$ reduction in surface carbon content after 15 minutes of UV-ozone.

The control sample, which had no surface treatment, showed a contact resistivity of $(2.63 \pm 0.43) \times 10^{-8} \Omega-\mathrm{cm}^{2}$, comparable to samples with only $\mathrm{NH}_{4} \mathrm{OH}$ or $\mathrm{HCl}$ etch rinse.

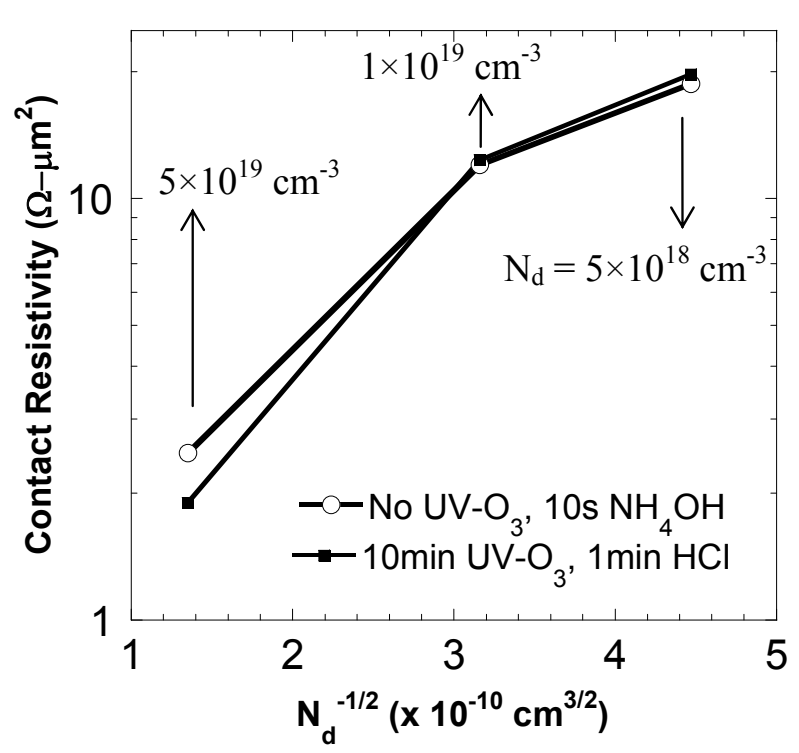

Fig 5: Contact resistivity $\left(\rho_{\mathrm{c}}\right)$ as a function of doping in the semiconductor for two different etch chemistries; $\rho_{\mathrm{c}}$ variation with $\mathrm{N}_{\mathrm{d}}$ shows that dominant electron transport mechanism from metal to semiconductor is tunneling

\section{B. Doping}

An increase in active dopants in the semiconductor results in a decrease in contact resistivity as shown in Fig 5. An order of magnitude decrease in doping from $5 \times 10^{19}$ to $5 \times 10^{18}$ $\mathrm{cm}^{-3}$ results in an increase in contact resistivity from $(1.90 \pm$ $0.35) \times 10^{-8} \Omega-\mathrm{cm}^{2}$ to $(19.71 \pm 2.07) \times 10^{-8} \Omega-\mathrm{cm}^{2}$ for 10 minute UV-Ozone, dilute $\mathrm{HCl}$ etch samples and from $(5.42 \pm$ $1.01) \times 10^{-8} \Omega-\mathrm{cm}^{2}$ to $(18.70 \pm 2.00) \times 10^{-8} \Omega-\mathrm{cm}^{2}$ for no UVozone \& concentrated ammonia etch samples. This increase suggests that for the highest semiconductor doping concentrations the dominant electron transport mechanism from TiW into the semiconductor is tunneling (11). For higher electron concentration, a shallower depletion at the metalsemiconductor interface exists, thereby decreasing the tunneling resistance and consequently the contact resistivity. We have also observed that an increase in "inactive" dopants keeping the same carrier concentration also reduces contact resistivity (12).

\section{Annealing}

Contact resistivity as a function of annealing temperature has been plotted in Fig 6. It is observed that for both types of chemical etching, the contacts are stable even after anneal at $400{ }^{\circ} \mathrm{C}$. After a one minute anneal at $400{ }^{\circ} \mathrm{C}$, the contact resistivity for 10 minute $\mathrm{UV}$-ozone, dilute $\mathrm{HCl}$ etch sample reduces from $(1.90 \pm 0.35) \times 10^{-8} \Omega-\mathrm{cm}^{2}$ to $(1.29 \pm 0.28) \times$ $10^{-8} \Omega-\mathrm{cm}^{2}$ and for 10 minute UV-ozone, concentrated ammonia etch from $(5.42 \pm 1.01) \times 10^{-8} \Omega-\mathrm{cm}^{2}$ to $(2.89 \pm$ $0.71) \times 10^{-8} \Omega-\mathrm{cm}^{2}$. 


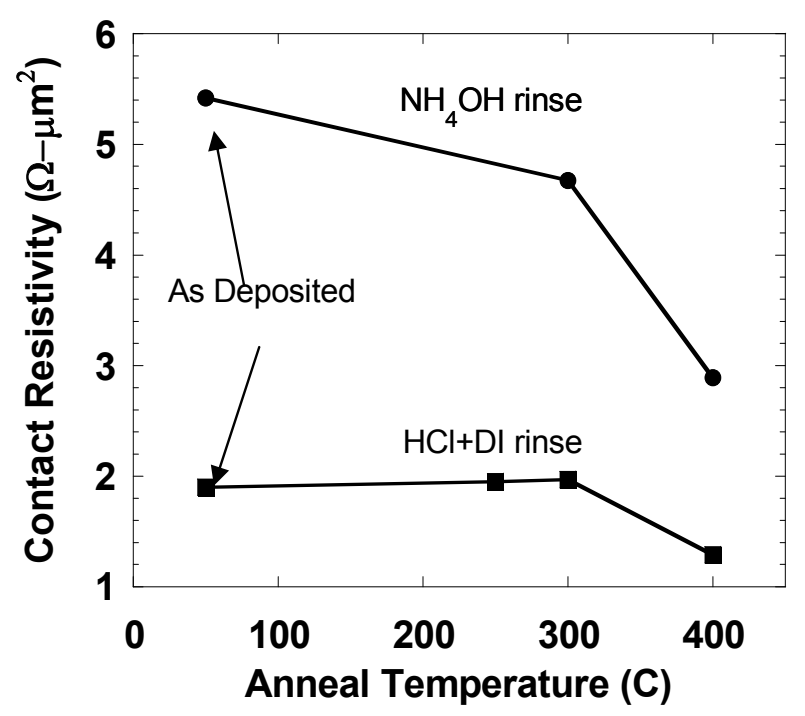

Fig 6: Variation in contact resistivity with annealing temperature for 1 minute anneal in $\mathrm{N}_{2}$ environment

\section{Error Analysis}

Error analysis is done to estimate systematic error in the contact resistivity as mentioned in (13). For the error analysis, error in TLM gaps measured using SEM is taken as $20 \mathrm{~nm}$ and in width as $0.2 \mu \mathrm{m}$ based on the resolution of the system. To estimate the random error in resistance measurements using the Agilent $4155 \mathrm{C}$, repeated measurements $(\sim 100)$ on the same TLM pad were done at different current bias with varied probe placement location. This analysis estimates the error in resistance $(\mathrm{dR})$ as $0.5 \mathrm{~m} \Omega$. Assuming the worst case offsets in bias current and voltage (14), and including the random error calculated above, the value of $\mathrm{dR}$ is calculated to be less than $5 \mathrm{~m} \Omega$. For a conservative estimate, $\mathrm{dR}$ is taken to be $50 \mathrm{~m} \Omega$ in the error analysis.

\section{CONCLUSION}

In summary, we report low resistance, ex-situ, and refractory TiW metal contacts to $\mathrm{n}^{+}-\mathrm{InGaAs}$ which are stable to at least $400{ }^{\circ} \mathrm{C}$. For high electron concentration of $5 \times 10^{19}$ $\mathrm{cm}^{-3}$ in n-InGaAs, 10 minutes of UV-ozone oxidation with one minute dilute $\mathrm{HCl}$ etch results in low contact resistivity of $(1.29 \pm 0.28) \times 10^{-8} \Omega-\mathrm{cm}^{2}$ after one minute anneal at $400{ }^{\circ} \mathrm{C}$. This resistivity is lower than the requisite value specified for greater than $1-\mathrm{THz} f_{\max }$ transistors and high current density operations. We observed that doping is the most important parameter that affects contact resistivity while different surface preparation techniques are of secondary influence. Dilute $\mathrm{HCl}$ etch is more effective in removing surface oxides compared to concentrated ammonia etch resulting in different contact resistivity variation trends with oxidation time for the two etchants. Thus, to obtain low contact resistivity, high doping in conjunction with an etch chemistry which fully removes surface oxides and annealing is required.

\section{ACKNOWLEDGMENTS}

This work was supported by the DARPA TFAST program N66001-02-C-8080. A portion of this work was done in the UCSB nanofabrication facility, part of the NSF funded NNIN network.

\section{REFERENCES}

(1) M.J.W. Rodwell, E. Lind, Z. Griffith, S.R. Bank, A.M. Cook, U. Singisetti, M. Wistey, G. Burek, A.C. Gossard; IEEE 19th Int. Conf on Indium Phosphide \& Related Materials, 2007. pp.9-13, 14-18 May 2007

(2) M.J.W. Rodwell et al.; IEEE Trans. on Electron Devices, vol.48, no.11, pp.2606-2624, Nov 2001

(3) M.J.W. Rodwell et al.; Compound Semiconductor Integrated Circuits Symp, 2008 CSICS '08, pp.1-3, 12-15 Oct. 2008

(4) E.F. Chor, R.J. Malik, R.A. Hamm, R. Ryan; Electron Device Letters, IEEE, vol.17, no.2, pp.62-64, Feb 1996

(5) Adam M. Crook, Erik Lind, Zach Griffith, Mark J. W. Rodwell, Jeremy D. Zimmerman, Arthur C. Gossard, Seth R. Bank; Appl. Phys. Lett. 91, 192114, 2007

(6) N. Braslau; J. of Vac. Sci. Technol, 19(3), Sept/Oct 1981

(7) G. Stareev, H. Kunzel, G. Dortmann; J of Appl. Phys., vol. 74, no. 12, pp. 7344-7356, Dec 1993

(8) T. Nittono, H. Ito, O. Nakajima, T. Ishibashi; Japanese J of Appl. Phys., vol. 27, no. 9, pp. 1718-1722, Sept 1988

(9) U. Singisetti, A.M. Crook, E. Lind, J.D. Zimmerman, M.A. Wistey, A.C. Gossard, M.J.W. Rodwell; Device Research Conf, 2007 65th Annual, pp.149-150, 18-20 June 2007

(10) G.K. Reeves, H.B. Harrison; IEEE Electron Devices Letters, vol. EDL-3, no. 5, pp. 111-113, May 1982

(11) S.M. Sze, Physics of Semiconductor Devices, $2^{\text {nd }}$ edition, pp 304-306

(12) Ashish K. Baraskar, M. Wistey, V. Jain, U. Singisetti, G. Burek, B.J. Thibeault, A.C. Gossard, M.J.W. Rodwell,; $36^{\text {th }}$ Conf on the Phys and Chem of Surfaces and Interfaces, PCSI36, Santa Barbara, 11-15 Jan 2009

(13) H. Ueng, D.B. Janes, K.J Webb; IEEE Trans on Electron Devices; vol 48, no.4, pp. 758-766, Apr 2008

(14) Agilent 4155C Semiconductor Parameter Analyzer Data Sheet; http://cp.literature.agilent.com/litweb/pdf/59889238EN.pdf 